\title{
Aspects of functioning and environmental factors in medical work capacity evaluations of persons with chronic widespread pain and low back pain can be represented by a combination of applicable ICF Core Sets
}

\author{
Urban Schwegler ${ }^{1,4}$, Jessica Anner ${ }^{2}$, Christine Boldt ${ }^{1,3}$, Andrea Glässel $^{1}$, Veronika Lay ${ }^{1}$, \\ Wout Ernst Lodewijk De Boer ${ }^{2}$, Gerold Stucki ${ }^{1,4}$ and Bruno Trezzini ${ }^{*}$
}

\begin{abstract}
Background: Medical work capacity evaluations play a key role in social security schemes because they usually form the basis for eligibility decisions regarding disability benefits. However, the evaluations are often poorly standardized and lack transparency as decisions on work capacity are based on a claimant's disease rather than on his or her functional capacity. A comprehensive and consistent illustration of a claimant's lived experience in relation to functioning, applying the International Classification of Functioning, Disability and Health (ICF) and the ICF Core Sets (ICF-CS), potentially enhances transparency and standardization of work capacity evaluations. In our study we wanted to establish whether and how the relevant content of work capacity evaluations can be captured by ICF-CS, using disability claimants with chronic widespread pain (CWP) and low back pain (LBP) as examples.

Methods: Mixed methods study, involving a qualitative and quantitative content analysis of medical reports. The ICF was used for data coding. The coded categories were ranked according to the percentage of reports in which they were addressed. Relevance thresholds at $25 \%$ and $50 \%$ were applied. To determine the extent to which the categories above the thresholds are represented by applicable ICF-CS or combinations thereof, measures of the ICF-CS' degree of coverage (i.e. content validity) and efficiency (i.e. practicability) were defined.

Results: Focusing on the 25\% threshold and combining the Brief ICF-CS for CWP, LBP and depression for CWP reports, the coverage ratio reached $49 \%$ and the efficiency ratio $70 \%$. Combining the Brief ICF-CS for LBP, CWP and obesity for LBP reports led to a coverage of $47 \%$ and an efficiency of $78 \%$.

Conclusions: The relevant content of work capacity evaluations involving CWP and LBP can be represented by a combination of applicable ICF-CS. A suitable standard for documenting such evaluations could consist of the Brief ICF-CS for CWP, LBP, and depression or obesity, augmented by additional ICF categories relevant for this particular context. In addition, the unique individual experiences of claimants have to be considered in order to assess work capacity comprehensively.
\end{abstract}

Keywords: International Classification of Functioning, Disability and Health (ICF), Work capacity evaluation, Chronic widespread pain, Low back pain, Standardization

\footnotetext{
* Correspondence: bruno.trezzini@paranet.ch

'Swiss Paraplegic Research (SPF), Nottwil, Switzerland

Full list of author information is available at the end of the article
} 


\section{Background}

Even though the process of disability evaluation varies between countries, medical work capacity evaluations usually play a crucial role in deciding on a claimant's eligibility for benefits provided by national disability insurance schemes. Because of the key role they play, such evaluations ought to be transparent and comprehensible for all persons involved [1-4]. To enhance transparency and comprehensibility, the claimant's lived experience in relation to his or her functioning as well as with regard to influencing contextual factors should be assessed comprehensively [2,5]. Moreover, the evaluations' comparability in terms of both interrater reliability between medical experts and content validity is considered as an important quality criterion [6-8]. Finally, standardization is seen as one means to ensure comparability in disability assessments $[9,10]$.

Medical standards usually refer to features which are considered as relevant to a target group in general and less so to individuals' unique experiences [11,12]. As a basis for comprehensive disability evaluations, however, a suitable standard should also allow the description of relevant experiences unique to the individual, thus complementing the whole process of evaluation [12].

In reality, decisions on work capacity often lack transparency and comprehensibility [10,13-15]. Also, disability assessments are often insufficiently standardized $[5,16,17]$, which affects their content validity and interrater reliability negatively $[8,9,17]$. In the Swiss national disability insurance scheme, for example, there is no generally accepted tool to guide the structure and content of disability evaluations [3]. Furthermore, decisions on work capacity for certain disorders are partly based on blanket rulings by the Swiss Federal Court [3]. Somatoform pain disorders, for instance, do generally not lead to incapacity for work. Because they are considered to be caused by psychosocial factors, the Swiss Social Security law does not recognize them as a sufficient reason for a disability pension, except if they are accompanied by a psychiatric co-morbidity like, for example, a depressive disorder [18]. By contrast, pain disorders caused by structural impairments (e.g. by a severe intervertebral disc disorder) normally entitle a person to receive disability benefits. However, diagnoses or impairments, are only loosely connected with functional limitations at work [19-21]. Moreover, the World Health Organization defines impairment as a loss or abnormality of a psychological, physiological, or anatomical structure or function and disability as a restriction or lack of ability to perform an activity in a manner considered to be normal for a human being [22]. Based on these definitions, focusing only on impairments is not sufficient to give a proper statement about a claimant's functional capacity at work.
Because pain is a subjective sensation, its impact on a claimant's functional capacity is difficult to objectify. Claimants with somatoform pain disorders could have the same or even a lower functional capacity than persons with a disorder related to a structural impairment. Nevertheless, according to Swiss jurisprudence their work capacity is usually rated higher. With respect to this controversy between the medical and the legal view, it seems crucial to apply a disability-oriented approach and to comprehensively assess the aspects which might influence a claimant's functioning and health in order to ensure transparent disability evaluations for persons with chronic pain.

Several attempts have been undertaken to enhance transparency and standardization in disability evaluations [23]. The Guides to the Evaluation of Permanent Impairment of the American Medical Association (AMA) are used for disability and impairment assessment and as a standard for workers' compensation evaluations in the United States and many English-speaking countries [24]. Furthermore, a number of standardized procedures for work capacity assessments have been developed like, for example, the Functional Capacity Evaluation (FCE) [25-27].

FCE, however, is not appropriate for multidisciplinary assessments as it is not geared towards a comprehensive evaluation of the claimant's functioning. It focuses on physical functional limitations and not on mental functioning [25], and it does not address environmental factors, an important component to ensure transparency in disability evaluations [5,28]. The AMA Guides have been questioned regarding their applicability in disability assessments of claimants with chronic pain [1], because they follow a diagnosis-based and impairment-oriented rather than a disability-oriented approach [29].

As part of the shift in recent years from impairmentoriented to disability-oriented assessments in European social security institutions, it has been suggested that the comprehensive conceptual framework and standardized taxonomy of the International Classification of Functioning, Disability and Health (ICF) [30] could improve the disability determination process [16,31-33]. Since the ICF offers a scientific basis for describing results and determinants of functioning, disability and health which also considers contextual factors [30], standardization and transparency in disability evaluations might be enhanced if the taxonomy would be used as a blueprint.

While the ICF framework was generally well-received, the actual application of the taxonomy has been hampered by the sheer number of categories to be assessed, i.e. 362 on the second level and up to 1,424 when applying the more detailed third and fourth levels. Consequently, ICF Core Sets (henceforth ICF-CS) have been 
developed in order to simplify the use of the taxonomy in clinical settings.

ICF-CS preserve the model of the ICF in a useable mode, and they come in two flavors: (1) brief ICF-CS include a minimum number of categories describing the most relevant aspects related to functioning in persons with a specific health condition or in a specific setting [34]; (2) comprehensive ICF-CS include all categories of the respective brief ICF-CS but also additional ones so as to facilitate multidisciplinary assessments in the clinical context [35].

Because they involve high costs and time resources of medical experts are limited, medical work capacity evaluations should not only be transparent but also efficient and practical [36]. ICF-CS allow to describe a person's lived experience in a comprehensive and systematic way [35], and might be applied as practical standards regarding what should be documented in disability assessments. So far there have been only few attempts to examine the applicability of ICF-CS in disability evaluations [16,37]. To ascertain their potential it is, therefore, vital to provide further empirical evidence.

Currently ICF-CS exist for about 30 health conditions [38]. The ICF-CS for chronic widespread pain (CWP) [39] and low back pain (LBP) [40] were published in 2004 and subsequently validated in the clinical context [41-43]. Due to the high prevalence of disability claims and large social costs based on CWP and LBP [44-47], we chose them as our index conditions. Both conditions are also often diagnosed concurrently [48].

Moreover, CWP has been found to be related to depression [49] and chronic LBP to obesity [50]. Such comorbidities are routinely addressed in disability assessments of claimants with chronic pain. We, therefore, also included in our analysis the ICF-CS for depression [51] and obesity [52].

\section{Objective}

The objective of the study was to establish whether or not and how the relevant content of medical work capacity evaluations can be captured by ICF-CS, using medical reports from disability claimants with the index conditions CWP and LBP as examples.

\section{Specific aims}

(1) We wanted to examine to what extent the relevant aspects of functioning and environmental factors in medical reports of claimants with CWP and LBP are represented by applicable ICF-CS. (2) We wanted to determine by which ICF-CS, or combinations thereof, these aspects are best represented.

\section{Methods}

\section{Study design}

A mixed methods study [53] was conducted, involving a qualitative and quantitative content analysis $[54,55]$ of medical reports. The ICF was used for data coding.

\section{Ethics}

The study was approved by the Ethics Commission of Basel, Switzerland, project number 134/08, and was performed in accordance with the Declaration of Helsinki.

\section{Sample}

The reports analyzed were derived from an elicitation of all medical reports received by the major Swiss health and accident insurers between February 1 and April 31, 2008 , as part of a study on the quality of medical work capacity evaluations in Switzerland [3]. Insurance employees selected and anonymized all reports containing a diagnosis of CWP and/or LBP based on the International Classification of Diseases (ICD-10) (see Table 1). The diagnoses were checked by two health professionals. To ensure comparability, only reports in German submitted to the Swiss national disability insurance scheme were selected. Reports in French and Italian as well as from accident, health and liability insurances were excluded.

From this basic sample a subsample was randomly drawn. The determination of the final sample size was based on two criteria: (1) heterogeneity, i.e. the relevant medical disciplines of pain-assessment and the index conditions (CWP, LBP) were to be included proportionally; and (2) saturation, i.e. the collected information was considered to be sufficient when no new secondlevel ICF category emerged in five successive reports analyzed [56-58]. In order to satisfy the heterogeneity requirement, i.e. a proportional inclusion of the medical disciplines and the index conditions, a minimum size of the subsample was determined.

\section{Analysis plan}

For the data analysis the sample was divided into two sub-groups: (1) reports with CWP diagnoses, and (2) reports with LBP diagnoses. Reports including both diagnoses entered the data analysis twice, once with the pure CWP and once with the pure LBP reports.

To examine the extent to which the relevant aspects of functioning and environmental factors in medical reports of claimants with CWP and LBP are represented by applicable ICF-CS, we first did a content analysis of the reports, using the ICF for data coding. We then ranked the coded categories for both sub-groups according to their relevance, i.e. their relative frequency across reports, setting thresholds at $25 \%$ and $50 \%$. Next, we examined whether the relevant ICF categories in CWP 
Table 1 ICD-10 diagnoses included in the sample

\begin{tabular}{|c|c|c|c|}
\hline \multicolumn{2}{|c|}{ ICD-10 diagnoses for CWP } & \multicolumn{2}{|c|}{ ICD-10 diagnoses for LBP } \\
\hline F45.0 & Somatization disorder & M42 & $\begin{array}{l}\text { Spinal osteochondrosis } \\
(.15-.17, .95-.97)\end{array}$ \\
\hline F45.1 & $\begin{array}{l}\text { Undifferentiated } \\
\text { somatoform disorder }\end{array}$ & M45 & Ankylosing spondylitis \\
\hline F45.4 & $\begin{array}{l}\text { Persistent somatoform } \\
\text { disorder }\end{array}$ & M46 & $\begin{array}{l}\text { Other inflammatory } \\
\text { spondylopathies }(.0, .1, .2, .3)\end{array}$ \\
\hline F54 & $\begin{array}{l}\text { Psychological and } \\
\text { behavioral factors associated } \\
\text { with disorders or diseases } \\
\text { classified elsewhere }\end{array}$ & M47 & $\begin{array}{l}\text { Spondylosis and } \\
\text { (osteo-)arthrosis of spine } \\
(.05-.07, .15-.17, .25-.27)\end{array}$ \\
\hline F62.8 & $\begin{array}{l}\text { Chronic pain personality } \\
\text { syndrome }\end{array}$ & M48 & $\begin{array}{l}\text { Other spondylopathies } \\
(.05-.07, .15-.17, .25-.27)\end{array}$ \\
\hline F32 & $\begin{array}{l}\text { Mild, moderate and severe } \\
\text { depressive episode, with } \\
\text { somatic symptoms }\end{array}$ & M51 & $\begin{array}{l}\text { Other intervertebral disc } \\
\text { disorders }(.0, .1)\end{array}$ \\
\hline F33 & $\begin{array}{l}\text { Recurrent depressive } \\
\text { disorder, with somatic } \\
\text { symptoms }\end{array}$ & M53 & $\begin{array}{l}\text { Other dorsopathies, not } \\
\text { elsewhere classified }(.25-.27 \text {, } \\
.3, .86-.87, .96-.97)\end{array}$ \\
\hline F34.1 & $\begin{array}{l}\text { Dysthymia (in relation with } \\
\text { pain) }\end{array}$ & M54 & $\begin{array}{l}\text { Dorsalgias }(.05-.07, .15-.17 \text {, } \\
.3, .4, .5, .85-.87)\end{array}$ \\
\hline F43.2 & Adjustment disorders & M99 & $\begin{array}{l}\text { Biomechanical lesions, not } \\
\text { elsewhere classified }(.03, .13 \text {, } \\
.23, .33, .43, .53, .63, .73, \\
.83, .93)\end{array}$ \\
\hline M79.7 & Fibromyalgia & & \\
\hline R52.2 & Other chronic pain & & \\
\hline R52.9 & Pain, unspecified & & \\
\hline
\end{tabular}

reports, i.e. the ones above the thresholds, are represented by the ICF-CS for the index condition (CWP) and major co-morbidities (LBP, depression). For LBP reports, we did the same analysis with the ICF-CS for the index condition (LBP) and major co-morbidities (CWP, obesity). By calculating and comparing values for their coverage (i.e. their content validity) and efficiency (i.e. their potential practicability) we determined to what extent the relevant aspects in the reports are represented by the ICF-CS for the index-condition, the co-morbidities, and a combination thereof and which ICF-CS or combination thereof is best representing these aspects.

\section{Analysis \\ Content analysis}

Our raw data consisted of reports on disability claimants. They comprised one or more medical disciplines and included information on: (a) socio-medical history, (b) medical examination, and (c) work capacity evaluation. This content was coded to the ICF by applying established linking rules $[59,60]$.

The reports were dissected into text passages, each representing a self-contained unit of meaning (e.g. "the claimant suffers from pain while walking"). The various concepts underlying a unit of meaning were determined (e.g. pain, walking) and coded to the most precise ICF category (e.g. b280 Sensation of pain, d450 Walking) by two health professionals trained in the ICF. A concept could be linked to more than one ICF category. Each instance of a category code being assigned to a concept was referred to as a coding. Concepts not appropriately codeable to ICF categories were flagged as either personal factors (e.g. individual attitudes and beliefs), not covered (e.g. degree of disability), not definable (e.g. demanding activities), or health condition (e.g. diabetes). The two coders assessed whether the categories represented limitations (e.g. "the claimant suffers from back pain") or, in case that they were environmental factors, whether they were barriers (e.g. "the surgery made the pain worse") or facilitators (e.g. "the surgery was helpful") for the claimant, were no problem (e.g. "the surgery had no effect"), or facts (e.g. "the surgery was performed recently"). Finally, the coders had to agree on the chosen codes. Any disagreement was solved in consultation with a third person experienced in the linking method.

\section{Reliability and saturation}

The interrater agreement was calculated using Cohen's kappa coefficient [61]. The saturation level was checked after each additional report analyzed.

\section{Relevance ranking}

Referring to the absolute frequency for determining relevance was deemed potentially misleading because different writing styles of medical experts could have led to varying degrees of content repetitions. Therefore, we operationalized the relevance of a coded category as its relative frequency across reports, i.e. the percentage of reports in which it appeared as a limitation, barrier or facilitator for the claimant. In order to ensure comparability with the ICF-CS, which refer to aspects that are problematic or supportive for the patients, we did not include the ICF categories assessed as no problem or facts in the ranking. Moreover, since the concepts not appropriately codeable with the ICF were not further specified in this study, they were not included in the ranking. Thus, the final ranking involved only secondlevel ICF categories coded either as a limitation, barrier or facilitator. For the ensuing data analysis we defined two thresholds of minimum relevance, the more lenient one at $25 \%$ or more of the reports, the more stringent one at $50 \%$ or more.

\section{Coverage and efficiency ratios}

We used two criteria to examine the extent to which the relevant content of medical reports involving CWP and LBP is represented by ICF-CS. (1) The coverage ratio, i.e. the ability of ICF-CS to capture the relevant aspects of the context in which they are applied (namely the index 


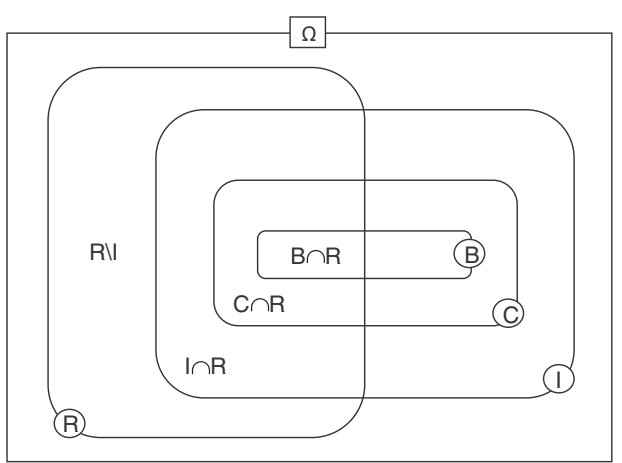

Note: $\Omega=$ all domains of human experience; $R=$ content of medical reports; $I=$ all 362

second-level ICF categories; C = Comprehensive ICF Core Set categories (for CWP or LBP); B =

Brief ICF Core Set categories (for CWP or LBP).

Figure 1 Operationalization of an ICF Core Set's coverage and efficiency ratios.

conditions CWP and LBP and the assessment of work capacity as part of disability evaluations). It was calculated as the number of ICF-CS categories above the threshold of $25 \%$ (or $50 \%$ ) divided by the total number of ICF categories above the threshold. (2) The efficiency ratio, i.e. the ability of ICF-CS to be manageable and to contain only as many categories as necessary. It was calculated as the number of ICF-CS categories above the threshold divided by the total number of categories in the ICF-CS. A definition of efficiency which is similar to ours was applied in a recent study where it was defined as the ability of a measurement instrument to be manageable and to contain as few items as possible that measure variables outside a domain set of ICF categories used in that study [62].

ICF-CS should ideally show a high coverage ratio and be efficient at the same time.

Referring to Figure 1, the operationalization of the coverage and efficiency ratios can be further illustrated as follows:

$$
\begin{aligned}
& \text { Coverage ratio (Brief } \mathrm{ICF}-\mathrm{CS})=(\mathrm{B} \cap \mathrm{R}) /(\mathrm{I} \cap \mathrm{R}) \\
& \text { Coverage ratio (Comprehensive } \mathrm{ICF}-\mathrm{CS}) \\
& =(\mathrm{C} \cap \mathrm{R}) /(\mathrm{I} \cap \mathrm{R})
\end{aligned}
$$

Efficiency ratio $($ Brief $\mathrm{ICF}-\mathrm{CS})=(\mathrm{B} \cap \mathrm{R}) / \mathrm{B}$

Efficiency ratio (Comprehensive ICF-CS)

$$
=(\mathrm{C} \cap \mathrm{R}) / \mathrm{C}
$$

\section{Results}

\section{Sample characteristics}

In order to satisfy the heterogeneity requirement, the required minimum sample size had been determined to be 72 medical reports, representing about one third of the basic sample of 209 reports. The saturation criterion was already reached after coding 30 reports. The number and type of disciplines in the reports are displayed in Table 2.

27 reports contained only a CWP diagnosis, 22 only a LBP diagnosis, and 23 both a CWP and LBP diagnosis. Of the 50 reports with CWP diagnoses, 24 (48\%) also included a diagnosis of the ICD-10-four-character subcategory "Mood [affective] disorders". Of the 45 reports with LBP diagnoses, 13 (29\%) additionally

\section{Table 2 Medical disciplines represented in the reports}

CWP LBP

Number of medical disciplines in report

\begin{tabular}{lcc} 
One & 20 & 14 \\
Two & 4 & 5 \\
More than two & 26 & 26 \\
Medical discipline & & \\
Psychiatry & 45 & 31 \\
Rheumatology & 21 & 22 \\
Internal medicine & 16 & 16 \\
Neurology & 10 & 11 \\
Orthopedics & 9 & 12 \\
General medicine & 11 & 9 \\
Neurosurgery & 1 & 5 \\
Orthopedic surgery & 1 & 3 \\
Neuropsychology & 1 & 3 \\
Pneumology & 1 & - \\
Hand surgery & 1 & 1 \\
Functional capacity evaluation & - & 1 \\
\hline
\end{tabular}


Table 3 Relative frequency ranking of the ICF categories found in the CWP reports $(n=50)$

\begin{tabular}{|c|c|c|c|c|c|c|c|c|c|c|}
\hline \multirow[t]{2}{*}{ Rank } & \multirow{2}{*}{$\begin{array}{l}\text { ICF } \\
\text { code }\end{array}$} & \multirow[t]{2}{*}{ ICF category } & \multicolumn{2}{|c|}{ CWP } & \multicolumn{2}{|c|}{ LBP } & \multicolumn{2}{|c|}{ Depression } & \multirow{2}{*}{$\begin{array}{c}\text { Relative } \\
\text { frequency } \\
(\%)\end{array}$} & \multirow{2}{*}{$\begin{array}{l}\text { Absolute } \\
\text { frequency }\end{array}$} \\
\hline & & & $\begin{array}{c}\text { Brief } \\
(k=24)\end{array}$ & $\begin{array}{c}\text { Compr. } \\
(k=67)\end{array}$ & $\begin{array}{c}\text { Brief } \\
(k=35)\end{array}$ & $\begin{array}{c}\text { Compr. } \\
(k=78)\end{array}$ & $\begin{array}{c}\text { Brief } \\
(k=31)\end{array}$ & $\begin{array}{l}\text { Compr. } \\
(\mathrm{k}=121)\end{array}$ & & \\
\hline 1 & b280 & Sensation of pain & $x$ & $x$ & $x$ & $x$ & . & $x$ & 100 & 2531 \\
\hline 2 & b152 & Emotional functions & $x$ & $x$ & $x$ & $x$ & $X^{*}$ & $x$ & 98 & 640 \\
\hline 3 & b130 & Energy and drive functions & $x$ & $x$ & $x$ & $x$ & $x^{*}$ & $x$ & 98 & 393 \\
\hline 4 & d850 & Remunerative employment & $x$ & $x$ & $x$ & $x$ & . & $x$ & 96 & 344 \\
\hline 5 & b126 & Temperament and personality functions & . & $x$ & . & $x$ & $x^{*}$ & $x$ & 94 & 445 \\
\hline 6 & b134 & Sleep functions & $x$ & $x$ & $x$ & $x$ & . & $x$ & 92 & 222 \\
\hline \multirow[t]{2}{*}{7} & e310 & Immediate family & $x$ & $x$ & $x$ & $x$ & $x$ & $x$ & 90 & 332 \\
\hline & e110† & Products or substances for personal consumption & $X^{*}$ & $x^{*}$ & $x$ & $x$ & $X^{*}$ & $x^{*}$ & 90 & 184 \\
\hline 8 & e580 & Health services, systems and policies & . & $x$ & $x$ & $x$ & $x$ & $x$ & 88 & 106 \\
\hline 9 & $d 240$ & Handling stress and other psychological demands & $x$ & $x$ & $x$ & $x$ & $x$ & $x$ & 86 & 177 \\
\hline 10 & d570 & Looking after one's health & & $x$ & & $x$ & $x$ & $x$ & 86 & 154 \\
\hline 11 & b270 & $\begin{array}{l}\text { Sensory functions related to temperature and other } \\
\text { stimuli }\end{array}$ & 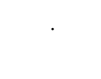 & $x$ & . & . & . & . & 82 & 225 \\
\hline \multirow[t]{2}{*}{12} & e1101 & Drugs & $x$ & $x$ & $X^{*}$ & $X^{*}$ & $x$ & $x$ & 82 & 140 \\
\hline & b160† & Thought functions & $X^{*}$ & $x^{*}$ & . & . & . & $x$ & 80 & 337 \\
\hline 13 & b730 & Muscle power functions & $x$ & $x$ & $x$ & $x$ & & . & 78 & 180 \\
\hline 14 & b710 & Mobility of joint functions & . & $x$ & $x$ & $x$ & . & . & 74 & 365 \\
\hline 15 & b1602 & Content of thought & $x$ & $x$ & & . & . & $x$ & 74 & 145 \\
\hline 16 & e570 & Social security services, systems and policies & $x$ & $x$ & $x$ & $x$ & . & $x$ & 74 & 130 \\
\hline 17 & s760 & Structure of trunk & & . & $x$ & $x$ & . & & 70 & 571 \\
\hline 18 & $d 415$ & Maintaining a body position & . & $x$ & $x$ & $x$ & . & . & 70 & 201 \\
\hline 19 & e165 & Assets & . & . & . & & & $x$ & 70 & 89 \\
\hline 20 & $d 450$ & Walking & $x$ & $x$ & $x$ & $x$ & . & . & 68 & 141 \\
\hline 21 & $d 760$ & Family relationships & $x$ & $x$ & $x$ & $x$ & $x$ & $x$ & 68 & 103 \\
\hline 22 & $\mathrm{~d} 230$ & Carrying out daily routine & $x$ & $x$ & . & . & $x^{*}$ & $x$ & 68 & 98 \\
\hline 23 & b435 & Immunological system functions & . & . & . & & & . & 64 & 207 \\
\hline 24 & b735 & Muscle tone functions & & $x$ & $x$ & $x$ & . & & 64 & 122 \\
\hline 25 & $d 430$ & Lifting and carrying objects & $x$ & $x$ & $x$ & $x$ & . & . & 64 & 104 \\
\hline 26 & b455 & Exercise tolerance functions & $x$ & $x$ & $x$ & $x$ & & . & 64 & 102 \\
\hline 27 & $\mathrm{~d} 870$ & Economic self-sufficiency & . & . & . & . & . & $x$ & 64 & 73 \\
\hline 28 & d920 & Recreation and leisure & $x$ & $x$ & & $x$ & . & $x$ & 64 & 66 \\
\hline 29 & $d 770$ & Intimate relationships & $x$ & $x$ & . & $x$ & $x$ & $x$ & 62 & 74 \\
\hline 30 & $d 410$ & Changing a basic body position & . & $x$ & $x$ & $x$ & . & & 58 & 84 \\
\hline 31 & $d 750$ & Informal social relationships & . & & . & . & . & $x$ & 58 & 53 \\
\hline 32 & s750 & Structure of lower extremity & . & . & . & $x$ & & . & 56 & 179 \\
\hline 33 & d845 & Acquiring, keeping and terminating a job & . & $x$ & $x$ & $x$ & $x$ & $x$ & 56 & 68 \\
\hline 34 & b140 & Attention functions & & $x$ & & . & $x$ & $x$ & 56 & 60 \\
\hline 35 & b147 & Psychomotor functions & $x$ & $x$ & . & . & $x$ & $x$ & 54 & 80 \\
\hline 36 & b144 & Memory functions & . & . & . & & & $x$ & 52 & 65 \\
\hline 37 & b530 & Weight maintenance functions & . & . & . & . & . & $x$ & 50 & 86 \\
\hline 38 & e565 & Economic services, systems and policies & . & . & . & . & . & . & 48 & 50 \\
\hline 39 & e410 & Individual attitudes of immediate family members & $x$ & $x$ & $x$ & $x$ & $x$ & $x$ & 46 & 72 \\
\hline 40 & e225 & Climate & & & & $x$ & . & $x$ & 44 & 53 \\
\hline
\end{tabular}


Table 3 Relative frequency ranking of the ICF categories found in the CWP reports $(\mathbf{n}=\mathbf{5 0})$ (Continued)

\begin{tabular}{|c|c|c|c|c|c|c|c|c|c|c|}
\hline 41 & $\mathrm{~d} 720$ & Complex interpersonal interactions & . & $x$ & . & . & . & $x$ & 44 & 45 \\
\hline 42 & d160 & Focusing attention & & $x$ & & . & . & . & 44 & 44 \\
\hline 43 & $d 475$ & Driving & . & $x$ & . & $x$ & . & $x$ & 44 & 38 \\
\hline 44 & b240 & $\begin{array}{l}\text { Sensations associated with hearing and vestibular } \\
\text { function }\end{array}$ & . & . & . & . & . & . & 42 & 47 \\
\hline 45 & b810 & Protective functions of skin & . & . & . & . & . & . & 42 & 39 \\
\hline 46 & d445 & Hand and arm use & & & & $x$ & . & & 40 & 56 \\
\hline 47 & b420 & Blood pressure functions & . & . & . & & & & 40 & 44 \\
\hline 48 & d350 & Conversation & . & . & . & . & $x$ & $x$ & 40 & 32 \\
\hline 49 & b460 & $\begin{array}{l}\text { Sensations associated with cardiovascular and } \\
\text { respiratory functions }\end{array}$ & & . & & . & . & $x$ & 38 & 44 \\
\hline 50 & $s 720$ & Structure of shoulder region & . & . & . & & & . & 38 & 43 \\
\hline 51 & b110 & Consciousness functions & . & . & . & . & . & . & 38 & 40 \\
\hline 52 & e325 & $\begin{array}{l}\text { Acquaintances, peers, colleagues, neighbours and } \\
\text { community members }\end{array}$ & . & $x$ & . & $x$ & $x$ & $x$ & 38 & 28 \\
\hline 53 & e315 & Extended family & . & . & . & . & . & . & 36 & 31 \\
\hline 54 & d440 & Fine hand use & & & & . & . & . & 34 & 52 \\
\hline 55 & b620 & Urination functions & . & . & . & $x$ & . & . & 34 & 42 \\
\hline 56 & b535 & Sensations associated with the digestive system & . & . & . & & & $x$ & 34 & 34 \\
\hline 57 & $\mathrm{e} 120$ & $\begin{array}{l}\text { Products and technology for personal indoor and } \\
\text { outdoor mobility and transportation }\end{array}$ & . & . & . & $x$ & . & . & 32 & 67 \\
\hline 58 & d640 & Doing housework & $x$ & $x$ & $x$ & $x$ & . & $x$ & 32 & 35 \\
\hline 59 & e245 & Time-related changes & . & . & . & . & . & $x$ & 32 & 35 \\
\hline 60 & b780 & $\begin{array}{l}\text { Sensations related to muscles and movement } \\
\text { functions }\end{array}$ & & $x$ & & $x$ & . & $x$ & 32 & 33 \\
\hline 61 & b415 & Blood vessel functions & . & . & . & . & . & . & 32 & 31 \\
\hline 62 & b510 & Ingestion functions & . & . & . & . & . & . & 32 & 24 \\
\hline 63 & d166 & Reading & . & . & . & . & . & $x$ & 32 & 16 \\
\hline 64 & b525 & Defecation functions & & & & . & . & & 30 & 33 \\
\hline 65 & b770 & Gait pattern functions & . & . & . & $x$ & & . & 30 & 31 \\
\hline 66 & s740 & Structure of pelvic region & . & . & . & $x$ & . & . & 30 & 30 \\
\hline 67 & d660 & Assisting others & & $x$ & & $x$ & . & $x$ & 28 & 27 \\
\hline 68 & s120 & Spinal cord and related structures & . & . & $x$ & $x$ & . & . & 28 & 27 \\
\hline 69 & b750 & Motor reflex functions & . & . & . & $x$ & & . & 28 & 26 \\
\hline 70 & d540 & Dressing & . & $x$ & $x$ & $x$ & . & $x$ & 28 & 25 \\
\hline 71 & e355 & Health professionals & $x$ & $x$ & $x$ & $x$ & $x$ & $x$ & 28 & 23 \\
\hline 72 & $d 455$ & Moving around & . & $x$ & . & $x$ & . & . & 28 & 20 \\
\hline 73 & e320 & Friends & & . & & . & $x$ & $x$ & 28 & 18 \\
\hline 74 & $d 740$ & Formal relationships & . & & . & . & . & . & 26 & 33 \\
\hline 75 & b164 & Higher-level cognitive functions & . & $x$ & . & & & $x$ & 26 & 25 \\
\hline 76 & b830 & Other functions of the skin & . & . & . & . & . & . & 26 & 20 \\
\hline 77 & s730 & Structure of upper extremity & . & . & . & . & . & & 24 & 45 \\
\hline 78 & e430 & Individual attitudes of people in positions of authority & & $x$ & & . & . & $x$ & 24 & 37 \\
\hline 79 & $d 460$ & Moving around in different locations & . & . & . & $x$ & . & . & 24 & 27 \\
\hline 80 & e510 & $\begin{array}{l}\text { Services, systems and policies for the production of } \\
\text { consumer goods }\end{array}$ & & . & & . & . & . & 24 & 24 \\
\hline 81 & $d 710$ & Basic interpersonal interactions & & & & $x$ & . & $x$ & 24 & 23 \\
\hline
\end{tabular}


Table 3 Relative frequency ranking of the ICF categories found in the CWP reports $(\mathbf{n}=\mathbf{5 0})$ (Continued)

\begin{tabular}{|c|c|c|c|c|c|c|c|c|c|c|}
\hline 82 & d950 & Political life and citizenship & . & . & . & . & . & $x$ & 24 & 21 \\
\hline 83 & b640 & Sexual functions & . & $x$ & . & $x$ & . & $x$ & 24 & 20 \\
\hline 84 & e115 & $\begin{array}{l}\text { Products and technology for personal use in daily } \\
\text { living }\end{array}$ & . & . & . & & . & & 24 & 19 \\
\hline 85 & d330 & Speaking & . & . & . & . & . & $x$ & 24 & 19 \\
\hline 86 & s320 & Structure of mouth & . & & & . & . & & 24 & 16 \\
\hline 87 & $d 620$ & Acquisition of goods and services & . & $x$ & & $x$ & . & $x$ & 24 & 14 \\
\hline \multicolumn{11}{|c|}{ Ranking of the remaining categories of the Brief ICF Core Sets for CWP, LBP and depression: } \\
\hline 92 & b740 & Muscle endurance functions & o. & $x$ & $x$ & $x$ & . & . & 22 & 17 \\
\hline 95 & e450 & Individual attitudes of health professionals & & $x$ & $x$ & $x$ & $x$ & $x$ & 20 & 14 \\
\hline 98 & e135 & Products and technology for employment & . & . & $x$ & $x$ & . & . & 18 & 18 \\
\hline 99 & s770 & $\begin{array}{l}\text { Additional musculoskeletal structures related to } \\
\text { movement }\end{array}$ & . & $x$ & $x$ & $x$ & . & . & 18 & 13 \\
\hline 100 & e550 & Legal services, systems and policies & . & . & $x$ & $x$ & . & . & 18 & 12 \\
\hline 103 & d859 & $\begin{array}{l}\text { Work and employment, other specified and } \\
\text { unspecified }\end{array}$ & & . & $x$ & $x$ & . & & 16 & 20 \\
\hline 116 & d163 & Thinking & . & . & . & . & $x$ & $x$ & 14 & 9 \\
\hline 117 & b760 & Control of voluntary movement functions & $x$ & $x$ & . & . & . & . & 14 & 8 \\
\hline 121 & b715 & Stability of joint functions & . & . & $x$ & $x$ & . & . & 14 & 7 \\
\hline 139 & e415 & Individual attitudes of extended family members & . & . & & . & $x$ & $x$ & 8 & 11 \\
\hline 161 & d530 & Toileting & . & . & $x$ & $x$ & . & . & 6 & 4 \\
\hline 185 & $d 510$ & Washing oneself & . & $x$ & . & $x$ & $x$ & $x$ & 4 & 2 \\
\hline 210 & d175 & Solving problems & $x$ & $x$ & & . & $x$ & $x$ & 2 & 1 \\
\hline 212 & e420 & Individual attitudes of friends & & $x$ & . & & $x$ & $x$ & 2 & 1 \\
\hline 221 & d177 & Making decisions & . & . & & . & $x$ & $x$ & 2 & 1 \\
\hline
\end{tabular}

Note: $\mathrm{k}=$ total number of categories in the respective ICF Core Set; $\dagger=$ ICF categories that were ignored in the ranking because the Brief and Comprehensive ICF Core Sets for CWP contain them on the more specific third level; $\mathrm{X}=$ included in the particular ICF Core Set (CWP, LBP or depression); ${ }^{*}=$ in the particular ICF Core Set the stated category is included at the next lower (third) or next higher (second) level.

involved a diagnosis related to "Obesity and other hyperalimentation".

The overall interrater agreement (Cohen's kappa) at the second ICF-level was $0.80(0.79-0.81$; $95 \%$ bootstrap confidence interval [63]).

\section{Reports with CWP diagnoses \\ Content analysis}

21,562 units of meaning gave rise to 45,365 (100\%) codings. 30,042 (66.2\%) represented links to ICF categories. The remainder $(15,323$ or $33.8 \%)$, i.e. R/I in Figure 1, were not classifiable appropriately with the ICF. Of these, 4,276 (9.4\%) codings represented personal factors, the as yet unspecified fifth component of the ICF. 4,094 (9\%) codings were labeled as not covered, 4,710 (10.4\%) as not definable, and 2,243 (4.9\%) as health condition.

\section{Relevance ranking}

76 ICF categories passed the $25 \%$ and 37 the $50 \%$ threshold and were identified as relevant for CWP reports.
Table 3 shows if the categories are included in the ICFCS for CWP, LBP and depression.

\section{Coverage and efficiency ratios}

Focusing on the more inclusive 25\% threshold, the relevant aspects of functioning and environmental factors in CWP reports are represented with a coverage of $29 \%$ [54\%] and an efficiency of $92 \%$ [61\%] by the Brief [Comprehensive] ICF-CS for CWP (see Table 4).

When combining the ICF-CS for CWP, LBP and depression, the coverage ratio of the Brief [Comprehensive] ICF-CS was with $49 \%$ [82\%] substantially higher and the efficiency ratio with $70 \%$ [47\%] lower compared to the ICF-CS for CWP.

\section{Reports with LBP diagnoses Content analysis}

21,707 units of meaning led to 42,116 (100\%) codings. $28,876(68.6 \%)$ represented ICF categories. Of the 13,240 (31.4\%) codings not classifiable appropriately with the ICF, 3,111 (7.4\%) were labeled as personal factors, 3,322 
Table 4 Coverage and efficiency ratios of the different ICF Core Sets for the CWP-reports $(n=50)$ and the two relevance thresholds

\begin{tabular}{|c|c|c|c|}
\hline & $\begin{array}{c}\text { Number of } \\
\text { overlapping } \\
\text { categories }\end{array}$ & $\begin{array}{l}\text { Coverage } \\
\text { ratio (\%) }\end{array}$ & $\begin{array}{l}\text { Efficiency } \\
\text { ratio (\%) }\end{array}$ \\
\hline \multicolumn{4}{|c|}{ Relevance threshold $\geq 25 \%(m=76)$} \\
\hline CWP Brief $(k=24)$ & 22 & 29 & 92 \\
\hline CWP Comprehensive $(k=67)$ & 41 & 54 & 61 \\
\hline LBP Brief $(k=35)$ & 29 & 38 & 83 \\
\hline LBP Comprehensive $(k=78)$ & 43 & 57 & 55 \\
\hline Depression Brief $(k=26 t)$ & 19 & 25 & 73 \\
\hline $\begin{array}{l}\text { Depression Comprehensive } \\
(\mathrm{k}=90 \dagger)\end{array}$ & 43 & 57 & 48 \\
\hline $\begin{array}{l}\text { CWP + LBP + Depression Brief } \\
\left(\mathrm{k}=53^{*}\right)\end{array}$ & 37 & 49 & 70 \\
\hline $\begin{array}{l}\text { CWP + LBP + Depression } \\
\text { Comprehensive }\left(k=131^{*}\right)\end{array}$ & 62 & 82 & 47 \\
\hline \multicolumn{4}{|c|}{ Relevance threshold $\geq 50 \%(m=37)$} \\
\hline CWP Brief $(k=24)$ & 19 & 51 & 79 \\
\hline CWP Comprehensive $(k=67)$ & 29 & 78 & 43 \\
\hline LBP Brief $(k=35)$ & 21 & 57 & 60 \\
\hline LBP Comprehensive $(k=78)$ & 26 & 70 & 33 \\
\hline Depression Brief $(k=26+)$ & 14 & 38 & 54 \\
\hline $\begin{array}{l}\text { Depression Comprehensive } \\
(\mathrm{k}=90 \dagger)\end{array}$ & 26 & 70 & 29 \\
\hline $\begin{array}{l}\text { CWP }+ \text { LBP }+ \text { Depression Brief } \\
\left(k=53+^{*}\right)\end{array}$ & 29 & 78 & 55 \\
\hline $\begin{array}{l}\text { CWP + LBP + Depression } \\
\text { Comprehensive }\left(k=1311^{*}\right)\end{array}$ & 36 & 97 & 27 \\
\hline
\end{tabular}

Note: $\mathrm{m}=$ total number of ranked categories above the respective threshold; $\mathrm{k}=$ total number of categories in the respective ICF Core Set: $t=$ categories aggregated on the second level (expect categories only available on the third level in the Comprehensive ICF Core Set); ${ }^{*}=$ adjusted for overlap between the categories of the three ICF Core Sets.

(7.9\%) as not covered, 4,236 (10.1\%) as not definable, and $2,571(6.1 \%)$ as health condition.

\section{Relevance ranking}

74 ICF categories passed the $25 \%$ and 33 the $50 \%$ threshold and were identified as relevant for LBP reports. Table 5 shows if the categories are included in the ICFCS for LBP, CWP and obesity.

\section{Coverage and efficiency ratios}

Focusing on the $25 \%$ threshold, the relevant aspects of functioning and environmental factors in LBP reports are represented with a coverage of $36 \%$ [58\%] and an efficiency of 77\% [55\%] by the Brief [Comprehensive] ICFCS for LBP (see Table 6).

When combining the ICF-CS for CWP, LBP and obesity, the coverage ratio of the Brief [Comprehensive]
ICF-CS was with $47 \%$ [80\%] substantially higher and the efficiency ratio with $78 \%$ [41\%] lower compared to the ICF-CS for LBP.

\section{Discussion}

We found that the relevant content of medical work capacity evaluations involving CWP and LBP can be captured to a considerable, albeit not perfect, extent by a combination of applicable ICF-CS. The relevant aspects of functioning and environmental factors in the reports were either represented by the ICF-CS for the index conditions (CWP, LBP) or for major co-morbidities (depression, obesity). In both groups of reports and for both relevance thresholds, a combination of the ICF-CS analyzed showed substantially higher coverage ratios than the condition-specific ICF-CS, i.e. they represented the relevant aspects of medical work capacity evaluations involving CWP and LBP to a higher extent. There is, however, a trade-off. Due to the increased number of categories when combining the ICF-CS, the efficiency ratios decreased considerably compared to the condition-specific ICF-CS in most cases.

An interesting finding with regard to the medical disciplines involved in the medical reports was that, in fact, psychiatry appeared in both groups of reports as the most frequent discipline. This clearly indicates the relevance of psychiatric assessments for multidisciplinary medical work capacity evaluations of persons with CWP and LBP and is also in line with the finding that a considerable percentage of our medical reports included a co-morbid disorder from the ICD-10 chapter "Mood [affective] disorders".

Overall, our results are in line with previous research in the field which found that the Comprehensive ICF-CS for CWP and LBP have a potential for structuring work capacity assessments [37].

Our findings are also in agreement with the recently developed ICF Core Sets for vocational rehabilitation [64] regarding the importance of highlighting the components activities, participation and environmental factors in the context of work and work capacity.

Finally, with regard to the generic core set for disability evaluation in social security [32] we feel that its lack of environmental factors may be a potential limitation if one aims for a comprehensive and transparent documentation of a claimant's work capacity. While the authors argue that environmental aspects are implicitly covered by the participation items, we found in our analysis of medical reports prepared in the context of disability evaluations that a number of environmental factors (e.g. e310 Immediate family; e165 Assets) are explicitly and frequently reported as barriers or facilitators for the claimants (see Tables 3 and 5). 
Table 5 Relative frequency ranking of the ICF categories found in the LBP reports $(n=45)$

\begin{tabular}{|c|c|c|c|c|c|c|c|c|c|c|}
\hline \multirow[t]{2}{*}{ Rank } & \multirow{2}{*}{$\begin{array}{l}\text { ICF } \\
\text { Code }\end{array}$} & \multirow[t]{2}{*}{ ICF Category } & \multicolumn{2}{|c|}{ LBP } & \multicolumn{2}{|c|}{ CWP } & \multicolumn{2}{|c|}{ Obesity } & \multirow{2}{*}{$\begin{array}{c}\text { Relative } \\
\text { Frequency } \\
\text { (\%) }\end{array}$} & \multirow{2}{*}{$\begin{array}{l}\text { Absolute } \\
\text { Frequency }\end{array}$} \\
\hline & & & $\begin{array}{c}\text { Brief } \\
(k=35)\end{array}$ & $\begin{array}{c}\text { Compr. } \\
(k=78)\end{array}$ & $\begin{array}{c}\text { Brief } \\
(k=24)\end{array}$ & $\begin{array}{c}\text { Compr. } \\
(k=67)\end{array}$ & $\begin{array}{l}\text { Brief } \\
(k=8)\end{array}$ & $\begin{array}{l}\text { Compr. } \\
(k=109)\end{array}$ & & \\
\hline 1 & b280 & Sensation of pain & $x$ & $x$ & $x$ & $x$ & . & $x$ & 100 & 2462 \\
\hline 2 & $d 415$ & Maintaining a body position & $x$ & $x$ & . & $x$ & . & $x$ & 100 & 289 \\
\hline 3 & s760 & Structure of trunk & $x$ & $x$ & . & & . & $x$ & 98 & 958 \\
\hline 4 & b710 & Mobility of joint functions & $x$ & $x$ & & $x$ & & $x$ & 98 & 490 \\
\hline 5 & d850 & Remunerative employment & $x$ & $x$ & $x$ & $x$ & . & $x$ & 91 & 325 \\
\hline 6 & b730 & Muscle power functions & $x$ & $x$ & $x$ & $x$ & . & . & 91 & 192 \\
\hline 7 & b270 & $\begin{array}{l}\text { Sensory functions related to temperature and other } \\
\text { stimuli }\end{array}$ & $\cdot$ & . & & $x$ & & . & 87 & 260 \\
\hline 8 & $d 450$ & Walking & $x$ & $x$ & $x$ & $x$ & $x$ & $x$ & 87 & 158 \\
\hline 9 & b735 & Muscle tone functions & $x$ & $x$ & . & $x$ & . & & 87 & 119 \\
\hline 10 & b134 & Sleep functions & $x$ & $x$ & $x$ & $x$ & & $x$ & 84 & 157 \\
\hline 11 & $d 430$ & Lifting and carrying objects & $x$ & $x$ & $x$ & $x$ & . & $x$ & 84 & 151 \\
\hline 12 & d570 & Looking after one's health & . & $x$ & . & $x$ & $x$ & $x$ & 82 & 122 \\
\hline 13 & b152 & Emotional functions & $x$ & $x$ & $x$ & $x$ & & $x$ & 80 & 446 \\
\hline 14 & b126 & Temperament and personality functions & & $x$ & . & $x$ & . & $x$ & 80 & 335 \\
\hline 15 & b130 & Energy and drive functions & $x$ & $x$ & $x$ & $x$ & $x$ & $x$ & 80 & 277 \\
\hline 16 & $d 410$ & Changing basic body position & $x$ & $x$ & . & $x$ & . & $x$ & 80 & 111 \\
\hline 17 & e110 & Products or substances for personal consumption & $x$ & $x$ & $x^{*}$ & $x^{*}$ & $x$ & $x$ & 78 & 188 \\
\hline 18 & e580 & Health services, systems and policies & $x$ & $x$ & . & $x$ & . & $x$ & 76 & 101 \\
\hline 19 & e310 & Immediate family & $x$ & $x$ & $x$ & $x$ & $x$ & $x$ & 73 & 171 \\
\hline 20 & b435 & Immunological system functions & & & . & . & . & $x$ & 71 & 171 \\
\hline 21 & e570 & Social security services, systems and policies & $x$ & $x$ & $x$ & $x$ & . & $x$ & 69 & 97 \\
\hline 22 & s750 & Structure of lower extremity & & $x$ & . & & . & $x$ & 64 & 275 \\
\hline 23 & b530 & Weight maintenance functions & & & . & & $x$ & $x$ & 64 & 81 \\
\hline 24 & e165 & Assets & . & & . & . & . & . & 64 & 57 \\
\hline 25 & b160 & Thought functions & . & & $x^{*}$ & $x^{*}$ & . & . & 62 & 202 \\
\hline 26 & $\mathrm{~d} 240$ & Handling stress and other psychological demands & $x$ & $x$ & $x$ & $x$ & $x$ & $x$ & 62 & 137 \\
\hline 27 & d920 & Recreation and leisure & & $x$ & $x$ & $x$ & . & $x$ & 62 & 73 \\
\hline 28 & $\mathrm{~d} 230$ & Carrying out daily routine & . & & $x$ & $x$ & . & . & 60 & 90 \\
\hline 29 & b420 & Blood pressure functions & & & . & 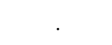 & . & $x$ & 60 & 40 \\
\hline 30 & $\mathrm{~d} 870$ & Economic self-sufficiency & & . & & & & $x$ & 58 & 55 \\
\hline 31 & $d 760$ & Family relationships & $x$ & $x$ & $x$ & $x$ & . & $x$ & 56 & 64 \\
\hline 32 & d845 & Acquiring, keeping and terminating a job & $x$ & $x$ & & $x$ & . & $x$ & 53 & 40 \\
\hline 33 & b455 & Exercise tolerance functions & $x$ & $x$ & $x$ & $x$ & . & $x$ & 51 & 57 \\
\hline 34 & $s 720$ & Structure of shoulder region & & . & . & . & . & & 49 & 48 \\
\hline 35 & e225 & Climate & . & $x$ & . & . & . & $x$ & 47 & 52 \\
\hline 36 & $d 445$ & Hand and arm use & . & $x$ & . & . & . & . & 44 & 49 \\
\hline 37 & b750 & Motor reflex functions & . & $x$ & & . & & . & 44 & 43 \\
\hline 38 & $d 750$ & Informal social relationships & . & & . & . & . & $x$ & 44 & 38 \\
\hline 39 & $d 455$ & Moving around & . & $x$ & & $x$ & $x$ & $x$ & 42 & 38 \\
\hline 40 & $d 770$ & Intimate relationships & & $x$ & $x$ & $x$ & . & $x$ & 42 & 35 \\
\hline 41 & b147 & Psychomotor functions & . & & $x$ & $x$ & . & . & 40 & 60 \\
\hline 42 & b770 & Gait pattern functions & & $x$ & . & & & & 40 & 42 \\
\hline
\end{tabular}




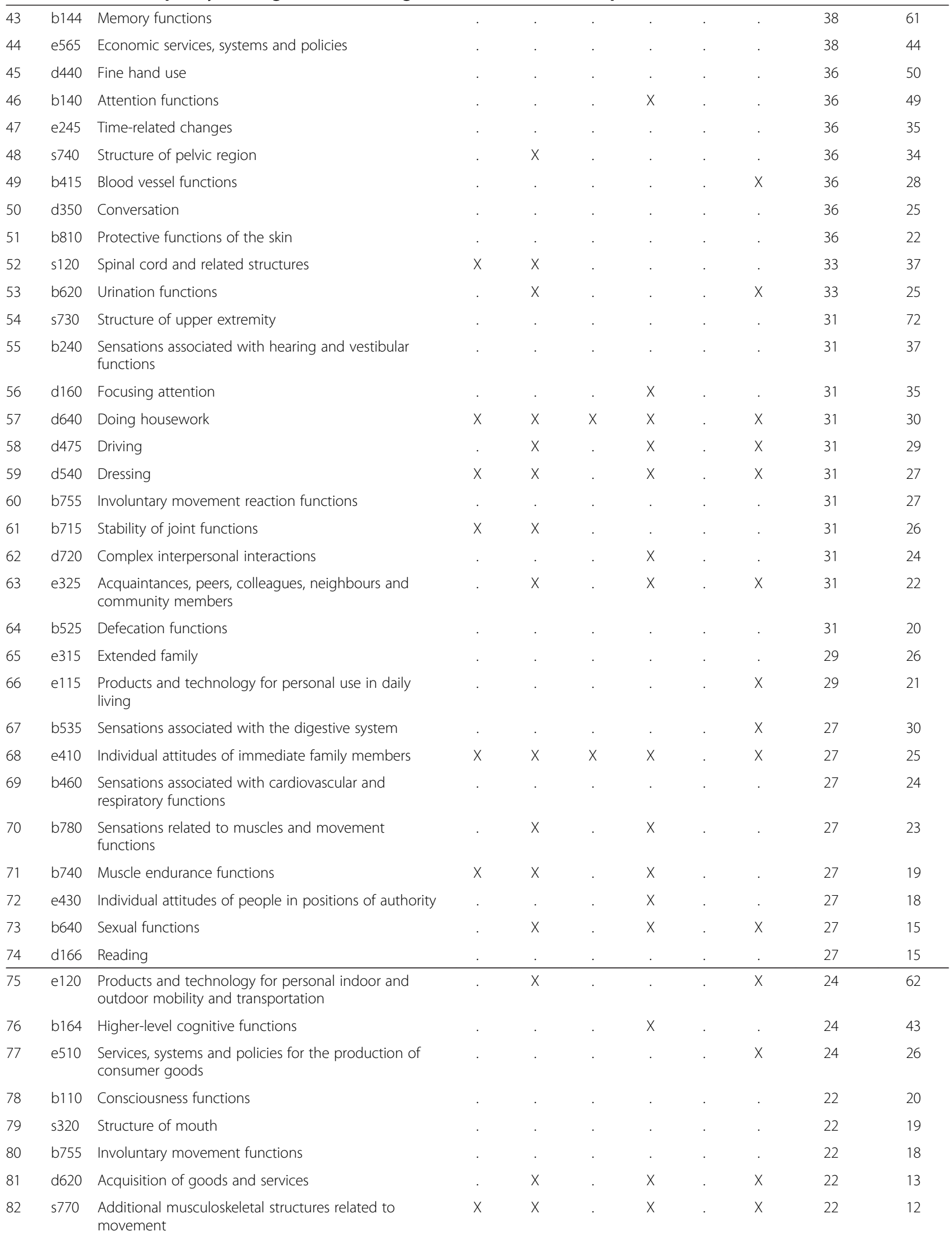


Table 5 Relative frequency ranking of the ICF categories found in the LBP reports $(\mathbf{n}=\mathbf{4 5})$ (Continued)

\begin{tabular}{|c|c|c|c|c|c|c|c|c|c|}
\hline \multicolumn{10}{|c|}{ Ranking of the remaining categories of the Brief ICF Core Sets for LBP, CWP and obesity: } \\
\hline 89 & e355 & Health professionals & $x$ & $x$ & $x$ & $x$ & $x$ & 20 & 11 \\
\hline 92 & d859 & $\begin{array}{l}\text { Work and employment, other specified and } \\
\text { unspecified }\end{array}$ & $x$ & $x$ & & & & 18 & 20 \\
\hline 94 & e135 & Products and technology for employment & $x$ & $x$ & . & . & . & 18 & 15 \\
\hline 103 & e450 & Individual attitudes of health professionals & $x$ & $x$ & . & $x$ & $x$ & 16 & 13 \\
\hline 104 & b760 & Control of voluntary movement functions & & . & $x$ & $x$ & & 16 & 13 \\
\hline 105 & e155 & $\begin{array}{l}\text { Design, construction and building products and } \\
\text { technology of buildings for private use }\end{array}$ & $x$ & $x$ & . & . & $x$ & 16 & 11 \\
\hline 122 & e550 & Legal services, systems and policies & $x$ & $x$ & & . & . & 11 & 13 \\
\hline 201 & d175 & Solving problems & . & & $x$ & $x$ & . & 2 & 1 \\
\hline - & d530 & Toileting & $x$ & $x$ & & & X & 0 & 0 \\
\hline
\end{tabular}

Note: $\mathrm{k}=$ total number of categories in the respective ICF Core Set; $\mathrm{X}=$ included in the particular ICF Core Set (LBP, CWP or obesity); ${ }^{*}=$ in the particular ICF Core Set the stated category is included at the next lower (third) or next higher (second) level.

Table 6 Coverage and efficiency ratios of the different ICF Core Sets for the LBP-reports $(n=45)$ and the two relevance thresholds

Number of
Coverage
Efficiency
categories

Relevance threshold $\geq 25 \%(m=74)$

\begin{tabular}{|c|c|c|c|}
\hline LBP Brief $(k=35)$ & 27 & 36 & 77 \\
\hline LBP Comprehensive $(k=78)$ & 43 & 58 & 55 \\
\hline CWP Brief $(k=24)$ & 21 & 28 & 88 \\
\hline CWP Comprehensive $(k=67)$ & 41 & 55 & 61 \\
\hline Obesity Brief $(k=8)$ & 8 & 11 & 100 \\
\hline $\begin{array}{l}\text { Obesity Comprehensive } \\
(\mathrm{k}=108+)\end{array}$ & 41 & 55 & 38 \\
\hline $\begin{array}{l}\text { LBP }+ \text { CWP + Obesity Brief } \\
\left(k=45+^{*}\right)\end{array}$ & 35 & 47 & 78 \\
\hline $\begin{array}{l}\text { LBP }+ \text { CWP + Obesity } \\
\text { Comprehensive }\left(k=143 \dagger^{*}\right)\end{array}$ & 59 & 80 & 41 \\
\hline \multicolumn{4}{|c|}{ Relevance threshold $\geq 50 \%(m=33)$} \\
\hline LBP Brief $(k=35)$ & 21 & 64 & 60 \\
\hline LBP Comprehensive $(k=78)$ & 25 & 76 & 32 \\
\hline CWP Brief $(k=24)$ & 17 & 52 & 71 \\
\hline CWP Comprehensive $(k=67)$ & 26 & 79 & 39 \\
\hline Obesity Brief $(k=8)$ & 7 & 21 & 88 \\
\hline $\begin{array}{l}\text { Obesity Comprehensive } \\
(\mathrm{k}=108+)\end{array}$ & 27 & 82 & 25 \\
\hline $\begin{array}{l}\text { LBP }+C W P+\text { Obesity Brief } \\
\left(k=45 t^{*}\right)\end{array}$ & 26 & 79 & 58 \\
\hline $\begin{array}{l}\mathrm{LBP}+\mathrm{CWP}+\text { Obesity } \\
\text { Comprehensive }\left(k=143 t^{*}\right)\end{array}$ & 32 & 97 & 22 \\
\hline
\end{tabular}

Note: $\mathrm{m}=$ total number of ranked categories above the respective threshold; $\mathrm{k}=$ total number of categories in the respective ICF Core Set(s); $\dagger=$ categories aggregated on the second level; ${ }^{*}=$ adjusted for overlap between the categories of the three ICF Core Sets.

\section{Study limitations}

Our study has some limitations. Our sample only included medical reports in German of the Swiss national disability insurance scheme with an ICD-10-diagnosis for CWP and/or LBP. The results may therefore not be generalizable to other health conditions, nor to other insurance schemes or other countries with different disability evaluation procedures. Future research should involve validation studies which look into the generalizability of our findings.

Another limitation was the significant amount of content not appropriately addressed in the current ICF taxonomy. This refers mainly to some specific aspects of functioning related to work capacity (e.g. demanding activities) and to personal factors, which may influence work capacity [65] and could, when explicitly addressed, contribute to more transparent disability evaluations [66]. This limitation could have potentially missed factors critical and relevant to the process of work capacity evaluation which should be taken into account in future research.

Finally, one could argue that context-specific ICF-CS relevant to the field of work capacity evaluation, like the ones for vocational rehabilitation or the generic core set for disability evaluation in social security, may have been included in our analysis as well. However, as our sample included medical reports with the index conditions CWP and LBP, we decided to focus rather on conditionspecific ICF-CS than on context-specific or generic ones. It might be an issue for further research to determine the extent to which these ICF-CS are representing the content of medical reports of disability claimants.

\section{Practical implications}

Combining ICF-CS (e.g. CWP with LBP and depression, or LBP with CWP and obesity) is a more 
effective approach for work capacity evaluations involving CWP and LBP than using solely conditionspecific ICF-CS. Taken together, the ICF-CS show a potential for guiding comprehensive multidisciplinary assessments. In particular, they could ensure transparency in disability evaluations as well as standardize them in terms of what should be documented. However, efficiency and practicability become problematic when simply combining ICF-CS due to the high number of categories to be assessed. To ensure high coverage and efficiency, a suitable standard for medical work capacity evaluations involving CWP and LBP could include:

(1) All categories of the Brief ICF-CS for the index conditions and major co-morbidities because Brief ICF-CS are considered as a minimum standard or data set to be reported in different settings so as to enhance comparability [35];

(2) Those categories of the Comprehensive ICF-CS identified as relevant for the present context;

(3) Those categories not included in the ICF-CS but identified as relevant for the present context (e.g. b435 Immunological system functions for CWP reports; e165 Assets for LBP reports).

Our relevance rankings display the categories which should be included in the standard. To ensure comprehensive evaluations, we recommend to focus on categories above the $25 \%$ threshold. Before being applied, however, future research would have to focus on a validation of the categories by experts in the field of work capacity evaluation.

Furthermore, the proposed ICF categories are the basis for a transparent documentation of those aspects of functioning which are relevant for a claimant's work capacity and should be seen as a complement to the claimant's diagnosis without necessarily having a direct implication on the work capacity decision itself. Whereas the categories can be used as a guideline for the evaluations in terms of what aspects should be documented, they are not addressing the issue of how these aspects should be assessed. This latter problem could be approached by assigning existing validated rating instruments to the suggested ICF categories.

Last but not least, it is important to emphasize that aspects of functioning which refer to the unique individual experience of a claimant, but are not necessarily addressed by the abovementioned ICF categories, should be considered in addition as complementary source of information to provide a comprehensive picture of the claimant.

\section{Conclusions}

The relevant content of medical work capacity evaluations involving CWP and LBP can be represented to a considerable extent by a combination of the ICF-CS for the index conditions and major co-morbidities. A suitable approach for a standardized documentation of the evaluations and for enhancing their transparency could consist of the Brief ICF-CS, augmented by additional ICF categories relevant for this particular context. Aspects not appropriately addressed in the current ICF taxonomy, such as personal factors, should be specified and eventually incorporated in such a standard as well. In addition, the unique individual experiences of claimants have to be taken into account in order to assess work capacity comprehensively.

\section{Competing interests}

The authors declare that they have no competing interests.

\section{Authors' contributions}

Urban Schwegler and Bruno Trezzini prepared the first draft of this paper. All other co-authors made substantial comments on the content of this manuscript. All authors read and approved the final manuscript.

\section{Acknowledgments}

We thank Jerome Bickenbach, Alarcos Cieza and Reuben Escorpizo for critical revisions to the manuscript. We also thank Heinrich Gall and Wolfgang Segerer for their support in preparing the database, and Cristina Bostan for her statistical expertise. We thank Katharina Karl for her support in linking the information of the medical reports, and Alarcos Cieza, Niklaus Gyr and Yvonne Bollag for their guidance and support in the planning, coordination and preparation of the study. This study was funded by Swiss Paraplegic Research (SPF) and the Academy of Swiss Insurance Medicine (asim).

\section{Author details}

${ }^{1}$ Swiss Paraplegic Research (SPF), Nottwil, Switzerland. ${ }^{2}$ asim, Academy of Swiss Insurance Medicine, University Hospital Basel, Basel, Switzerland. ${ }^{3}$ Department of Applied Social Sciences, University of Applied Sciences Munich, München, Germany. ${ }^{4}$ Department of Health Sciences and Health Policy, University of Lucerne and SPF, Nottwil, Switzerland.

Received: 21 July 2012 Accepted: 6 December 2012 Published: 18 December 2012

\section{References}

1. Robinson JP, Turk DC, Loeser JD: Pain, impairment, and disability in the AMA guides. J Law Med Ethics 2004, 32(2):315-326.

2. Ludwig CA: Anforderungen an Gutachten - Anforderungen an Gutachter. Schweizerische Ärztezeitung 2006, 87(23):1035-1036.

3. Stöhr S, Bollag Y, Auerbach H, Eichler K, Imhof D, Fabbro T, Gyr N: Quality assessment of a randomly selected sample of Swiss medical expertises - a pilot study. Swiss Med Wkly 2011, 141:w13173.

4. Cochiarella L, Andersson GBJ: Guides to the Evaluation of Permanent Impairment. 5th edition. Chicago: AMA Press; 2001.

5. Francescutti C, Gongolo F, Simoncello A, Frattura L: Description of the person-environment interaction: methodological issues and empirical results of an Italian large-scale disability assessment study using an ICF-based protocol. BMC Publ Health 2011, 11(suppl 4):S11.

6. Demeter SL, Andersson GBJ, Smith GM: Disability evaluation. St. Louis: Mosby and the American Medical Association; 1996.

7. Innes E, Straker L: Attributes of excellence in work-related assessments. Work 2003, 20(1):63-76.

8. Rudbeck M, Fonager $\mathrm{K}$ : Agreement between medical expert assessments in social medicine. Scand J Public Health 2011, 39(7):766-772.

9. Spanjer J, Krol B, Brouwer S, Groothoff JW: Sources of variation in work disability assessment. Work 2010, 37(4):405-411. 
10. Matheson LN, Kane M, Rodbard D: Development of new methods to determine work disability in the United States. J Occup Rehabil 2001, 11(3):143-154

11. Brunsson N, Jacobsson B: A world of standards. Oxford: Oxford University Press; 2000.

12. Timmermans S, Berg M: The gold standard: the challenge of evidence-based medicine and standardization in health care. Philadelphia: Temple University Press; 2003.

13. Social Security Administration: Plan for a new disability claim process. Washington, DC: Social Security Administration; 1994

14. Social Security Advisory Board: Charting the future of social security's disability programs: The need for fundamental change. Washington, DC: Social Security Advisory Board; 2001

15. de Boer WE, Rijkenberg AM, Donceel P: Guidelines for assessment of work disability: an international survey. Gesundheitswesen 2011, 73(6):e103-e110.

16. Kirschneck M, Winkelmann A, Kirchberger I, Glässel A, Ewert T, Stucki G, Cieza A: Anwendung der ICF Core Sets in der Begutachtung von Patienten mit lumbalen Rückenschmerzen und generalisiertem Schmerzsyndrom. Gesundheitswesen 2008, 70(11):674-678.

17. Spanjer J, Krol B, Brouwer S, Popping R, Groothoff JW, van der Klink JJ: Reliability and validity of the Disability Assessment Structured Interview (DASI): a tool for assessing functional limitations in claimants. J Occup Rehabil 2010, 20(1):33-40.

18. Meyer-Blaser U: Der Rechtsbegriff der Arbeitsunfähigkeit und seine Bedeutung in der Sozialversicherung, namentlich für den Einkommensvergleich in der Invalidenversicherung. Schriftenreihe des Institutes für Rechtswissenschaft und Rechtspraxis IRP-HSG St Gallen 2003, 23:27-119.

19. Loeser JD, Sullivan M: Doctors, diagnosis, and disability: a disastrous diversion. Clin Orthop Relat Res 1997, 336(336):61-66.

20. Jeger J: Somatoforme Schmerzstörungen - Medizin und Recht im Widerspruch? Eine Beurteilung aus ärztlicher Sicht. Ther Umsch 2007 64(8):415-423

21. Ehrlich GE, Wolfe F: On the difficulties of disability and its determination Rheum Dis Clin North Am 1996, 22(3):613-621.

22. Wood PH: The language of disablement: a glossary relating to disease and its consequences. Int Rehabil Med 1980, 2(2):86-92.

23. Spanjer J, Groothoff JW, Brouwer S: Instruments used to assess functional limitations in workers applying for disability benefit: a systematic review. Disabil Rehabil 2011, 33(23-24):2143-2150.

24. Rondinelli RD: American Medical Association's Guides to the Evaluation of Permanent Impairment. 6th edition. Chicago: AMA Press; 2008

25. Harten JA: Functional capacity evaluation. Occup Med 1998, 13(1):209-212.

26. Wind $H$, Gouttebarge V, Kuijer PP, Sluiter JK, Frings-Dresen MH: The utility of functional capacity evaluation: the opinion of physicians and other experts in the field of return to work and disability claims. Int Arch Occup Environ Health 2006, 79(6):528-534.

27. Wind H, Gouttebarge V, Kuijer PP, Sluiter JK, Frings-Dresen MH: Effect of Functional Capacity Evaluation information on the judgment of physicians about physical work ability in the context of disability claims. Int Arch Occup Environ Health 2009, 82(9):1087-1096.

28. Jahiel Rl, Scherer MJ: Initial steps towards a theory and praxis of person-environment interaction in disability. Disabil Rehabil 2010, 32(17):1467-1474.

29. Rondinelli RD: Commentary on Reliability of the AMA Guides to the Evaluation of Permanent Impairment. J Occup Environ Med 2010, 52(12):1204-1205

30. World Health Organization: International Classification of Functioning, Disability and Health (ICF). Geneva: World Health Organization; 2001.

31. Stucki G: International Classification of Functioning, Disability, and Health (ICF): a promising framework and classification for rehabilitation medicine. Am J Phys Med Rehabil 2005, 84(10):733-740.

32. Brage S, Donceel P, Falez F: Development of ICF core set for disability evaluation in social security. Disabil Rehabil 2008, 30(18):1392-1396.

33. Madden R, Glozier N, Mpofu E, Llewellyn G: Eligibility, the ICF and the UN convention: Australian perspectives. BMC Publ Health 2011 11(suppl 4):S6

34. Biering-Sorensen $F$, Scheuringer M, Baumberger M, Charlifue SW, Post MW Montero F, Kostanjsek N, Stucki G: Developing core sets for persons with spinal cord injuries based on the International Classification of Functioning, Disability and Health as a way to specify functioning. Spinal Cord 2006, 44(9):541-546.
35. Cieza A, Ewert T, Ustün TB, Chatterji S, Kostanjsek N, Stucki G: Development of ICF Core Sets for patients with chronic conditions. J Rehabil Med 2004, 36(suppl 44):9-11.

36. Gouttebarge V, Wind H, Kuijer PP, Sluiter JK, Frings-Dresen MH: How to assess physical work-ability with Functional Capacity Evaluation methods in a more specific and efficient way? Work 2010, 37(1):111-115.

37. Schult ML, Ekholm J: Agreement of a work-capacity assessment with the World Health Organisation International Classification of Functioning, Disability and Health pain sets and back-to-work predictors. Int J Rehabil Res 2006, 29(3):183-193.

38. ICF Core Set projects. http://www.icf-research-branch.org/icf-core-setsprojects.html.

39. Cieza A, Stucki G, Weigl M, Kullmann L, Stoll T, Kamen L, Kostanjsek N, Walsh N: ICF Core Sets for chronic widespread pain. J Rehabil Med 2004, 36(suppl 44):63-68.

40. Cieza A, Stucki G, Weigl M, Disler P, Jackel W, van der Linden S, Kostanjsek N, de Bie R: ICF Core Sets for low back pain. J Rehabil Med 2004, 36(suppl 44):69-74.

41. Hieblinger R, Coenen M, Stucki G, Winkelmann A, Cieza A: Validation of the International Classification of Functioning, Disability and Health Core Set for chronic widespread pain from the perspective of fibromyalgia patients. Arthritis Res Ther 2009, 11(3):R67.

42. Bautz-Holter E, Sveen U, Cieza A, Geyh S, Roe C: Does the International Classification of Functioning, Disability and Health (ICF) core set for low back pain cover the patients' problems? a cross-sectional contentvalidity study with a Norwegian population. Eur J Phys Rehabil Med 2008, 44(4):387-397.

43. Kirschneck M, Kirchberger I, Amann E, Cieza A: Validation of the comprehensive ICF core set for low back pain: the perspective of physical therapists. Man Ther 2011, 16(4):364-372.

44. Silverman S, Dukes EM, Johnston SS, Brandenburg NA, Sadosky A, Huse DM: The economic burden of fibromyalgia: comparative analysis with rheumatoid arthritis. Curr Med Res Opin 2009, 25(4):829-840.

45. Wasiak R, Kim J, Pransky G: Work disability and costs caused by recurrence of low back pain: longer and more costly than in first episodes. Spine 2006, 31(2):219-225.

46. Zimmermann M: Der chronische Schmerz. Epidemiologie und Versorgung in Deutschland. Der Orthopäde 2004, 4:508-514.

47. Oggier W: Volkswirtschaftliche Kosten chronischer Schmerzen in der Schweiz - eine erste Annäherung. Schweizerische Ärztezeitung 2007, 88(29/30):1265-1269.

48. Friedrich M, Hahne J, Wepner F: A controlled examination of medical and psychosocial factors associated with low back pain in combination with widespread musculoskeletal pain. Phys Ther 2009, 89(8):786-803.

49. Kato K, Sullivan PF, Evengard B, Pedersen NL: Chronic widespread pain and its comorbidities: a population-based study. Arch Intern Med 2006, 166(15):1649-1654.

50. van Oostrom SH, Monique Verschuren WM, de Vet HC, Picavet HS: Ten year course of low back pain in an adult population-based cohort - the Doetinchem Cohort Study. Eur J Pain 2011, 21:21.

51. Cieza A, Chatterii S, Andersen C, Cantista P, Herceg M, Melvin J, Stucki G, de Bie R: ICF Core Sets for depression. J Rehabil Med 2004, 36(suppl 44):128-134.

52. Stucki A, Daansen P, Fuessl M, Cieza A, Huber E, Atkinson R, Kostanjsek N, Stucki G, Ruof J: ICF Core Sets for obesity. J Rehabil Med 2004, 36(suppl 44):107-113.

53. Creswell JW, Plano-Clark VL: Designing and conducting mixed methods research. Thousand Oaks, CA: SAGE Publications; 2006.

54. Miller DC, Salkind NJ: Handbook of research design and social measurement. 6th edition. Thousand Oaks: Sage; 2002

55. Lee F, Peterson C: Content analysis of archival data. J Consult Clin Psychol 1997, 65(6):959-969.

56. Patton M: Qualitative evaluation and research methods. Newbury Park: Sage; 1990.

57. Glaser B, Strauss A: Discovery of grounded theory. Strategies for qualitative research. Chicago: Aldine Publishing Company; 1967.

58. Coenen M: Developing a method to validate the WHO ICF Core Sets from the patient perspective: rheumatoid arthritis as a case in point, $\mathrm{PhD}$ thesis. Munich: Ludwig-Maximilians-University; 2008

59. Cieza A, Brockow T, Ewert T, Amman E, Kollerits B, Chatterji S, Ustün TB, Stucki G: Linking health-status measurements to the International Classification of Functioning, Disability and Health. J Rehabil Med 2002, 34(5):205-210. 
60. Cieza A, Geyh S, Chatterij S, Kostanjsek N, Ustün B, Stucki G: ICF linking rules: an update based on lessons learned. J Rehabil Med 2005, 37(4):212-218.

61. Cohen J: A coefficient of agreement for nominal scales. Educ Psychol Meas 1960, 20:37-46.

62. Fekete C, Boldt C, Post M, Eriks-Hoogland I, Cieza A, Stucki G: How to measure what matters: development and application of guiding principles to select measurement instruments in an epidemiologic study on functioning. Am J Phys Med Rehabil 2011, 90(11 Suppl 2):S29-S38.

63. Efron B: Bootstrap methods: another look at the jackknife. Ann Stat 1979, 7(1):1-26.

64. Finger ME, Escorpizo R, Glässel $\mathrm{A}$, Gmünder HP, Lückenkemper M, Chan C, Fritz J, Studer U, Ekholm J, Kostanjsek N, et al: ICF Core Set for vocational rehabilitation: results of an international consensus conference. Disabil Rehabil 2012, 34(5):429-438.

65. Mitra S: The capability approach and disability. J Disabil Pol Stud 2006, 16(4):236-247.

66. Slebus FG, Sluiter JK, Kuijer PP, Willems JH, Frings-Dresen MH: Work-ability evaluation: a piece of cake or a hard nut to crack? Disabil Rehabil 2007, 29(16):1295-1300.

doi:10.1186/1471-2458-12-1088

Cite this article as: Schwegler et al:: Aspects of functioning and environmental factors in medical work capacity evaluations of persons with chronic widespread pain and low back pain can be represented by a combination of applicable ICF Core Sets. BMC Public Health 2012 12:1088.

\section{Submit your next manuscript to BioMed Central and take full advantage of:}

- Convenient online submission

- Thorough peer review

- No space constraints or color figure charges

- Immediate publication on acceptance

- Inclusion in PubMed, CAS, Scopus and Google Scholar

- Research which is freely available for redistribution 